\section{Avaliação Clínica e da Função Muscular em Pacientes Com Hipotiveoidismo Subclínico}

\section{RESUMO}

Alguns sintomas e sinais de hipotireoidismo, bem como alterações laboratoriais, podem estar presentes no hipotireoidismo subclínico (HS). Este trabalho avalia a prevalência de sintomas e sinais de hipotireoidismo e alterações músculo-esqueléticas em pacientes com HS ( $n=57) \mathrm{com}$ parado a um grupo controle sem disfunção tireoideana $(n=37)$. Baseado na presença de sintomas e sinais de hipotireoidismo, os participantes receberam pontuação específica (escore clínico). A força muscular foi aferida pelo teste muscular manual e por dinamômetro de cadeira e a força inspiratória por manovacuômetro. Os níveis de hormônios tireoideanos e enzimas musculares foram dosados. $\mathrm{O}$ grupo HS apresentou escore mais elevado $(p<0,01)$, maior freqüência das queixas de mialgia e fraqueza $(p<0,05)$ e redução de força das cinturas escapular e pélvica $(p<0,05)$. Os níveis médios de $T_{4}$ livre foram menores no HS $(p<$ $0,001)$. Os resultados sugerem que a presença de sintomas e sinais de disfunção tireoideana e níveis de $\mathrm{T}_{4}$ livre na faixa inferior da normalidade no HS possam estar relacionados e devem ser valorizados na decisão de iniciar $\mathrm{LT}_{4}$. (Arq Bras Endocrinol Metab 2006;50/3:523-531)

Descritores: Hipotireoidismo; Sinais e sintomas; Músculos; Anormalidades

\section{ABSTRACT}

Clinical and Muscular Evaluation in Patients With Subclinical Hypothyroidism.

Some symptoms and signs of hypothyroidism, as well as some laboratory abnormalities, may be present in subclinical hypothyroidism (SH). This study evaluates the prevalence of signs and symptoms of hypothyroidism and skeletal muscle dysfunction in 57 patients with $\mathrm{SH}$ compared to 37 euthyroid controls. The participants received a clinical score based on signs and symptoms of hypothyroidism. The muscle strength was estimated by manual testing and chair dynamometer and inspiratory force by manuvacuometer. Thyroid hormones and muscle enzymes were measured. The SH group presented with higher score $(p<0.01)$, complained about mialgia and weakness more frequently $(p<0.05)$, and showed strength disability in scapular and pelvic girdles $(\mathrm{p}<0.05)$. The median free $\mathrm{T}_{4}$ serum levels were lower in $\mathrm{SH}(\mathrm{p}<0.001)$. These findings suggest that signs and symptoms of thyroid dysfunction may be related to lower levels of $\mathrm{FT}_{4}$ in $\mathrm{SH}$ and should be taken into account in the decision of beginning $\mathrm{LT}_{4}$ therapy. (Arq Bras Endocrinol Metab 2006;50/3:523-531)

Keywords: Hypothyroidism; Sings and symptoms; Muscles; Abnormalities

\section{artigo original}

Vaneska Spinelli Reuters Alexandru Buescu

Fabiola A. Aarão Reis

Cloyva Paiva Almeida

Patricia F. dos S. Teixeira Antônio J. Leal Costa

Márcia Branco Wagman

Márcia Martins Ferreira

Carmen Lucia N. de Castro Mario Vaisman

Faculdade de Medicina da Universidade Federal do Rio de Janeiro e Serviços de Endocrinologia e Medicina Física e Reabilitação do Hospital

Universitário Clementino

Fraga Filho e Núcleo de Estudos de Saude Coletiva UFRJ, $R$ io de Janeiro, $R J$.

Recebido em 03/01/05

Revisado em 05/12/05 Aceito em 09/03/06 
O TERMO hipotireoidismo SUbCLínico (HS) tem sido definido como níveis elevados de tireotropina $(\mathrm{TSH})$ e níveis normais de tiroxina $\left(\mathrm{T}_{4}\right)$ e triiodotironina $\left(\mathrm{T}_{3}\right)$ e de suas respectivas frações livres (1). Embora essa classificação seja primordialmente bioquímica, há evidências de que algumas manifestações descritas para o hipotireoidismo manifesto (HM) estejam presentes no HS, e que possivelmente fosse mais apropriada a denominação hipotireoidismo leve e disfunção mínima de tireóide (2). Alguns trabalhos mostraram maior freqüência de sintomas e sinais de hipotireoidismo $(3,4)$, maior prevalência de sintomas neuromusculares e de alterações da força muscular $(5,6)$, alterações do perfil lipídico e aumento do risco cardiovascular (7-9) e maior freqüência de distúrbios do humor $(10,11)$.

A prevalência de HS na população adulta varia de $1 \%$ a $10 \%(12,13)$ e pode chegar a $21 \%$ em mulheres com idade superior a 60 anos (14). O curso natural do HS ainda não está bem esclarecido, mas sabese que em pacientes com anticorpos antitireoideanos positivos a taxa de progressão para hipotireoidismo varia de $4 \%$ a $18 \%$ ao ano (em média $5 \%)(15,16)$. Associação entre níveis de TSH e anticorpos antitireoideanos positivos também tem sido encontrada (17), e alguns autores têm indicado níveis elevados de TSH como uma das indicações para o tratamento com Levotiroxina $\left(\mathrm{LT}_{4}\right)$. Não existe, contudo, consenso definitivo para o tratamento com $\mathrm{LT}_{4}$ (18-21).

Objetivamos com o presente trabalho avaliar a freqüência de sintomas e sinais de hipotireoidismo, bem como queixas neuromusculares e alterações da força muscular em pacientes com HS comparando-as a um grupo controle eutireoideano, que possam servir de base para um trabalho futuro acerca dos benefícios do tratamento com levotiroxina em pacientes com HS.

\section{PACIENTES E MÉTODOS}

\section{Desenho do estudo}

Trata-se de um estudo seccional envolvendo dois grupos de estudo: um composto por pacientes com HS e outro por indivíduos eutireoideanos.

\section{Seleção dos grupos}

No período de março de 2001 a outubro de 2003, foram avaliados seqüencialmente 203 pacientes com hipotireoidismo subclínico no ambulatório de Endocrinologia do Hospital Universitário Clementino Fraga Filho (HUCFF), UFRJ, e, desses, um total de $\mathbf{5 7}$ foram selecionados. Definiu-se como hipotireoidismo sub- clínico níveis elevados de TSH (acima de $4 \mu \mathrm{U} / \mathrm{mL}$ ) e $\mathrm{T}_{4}$ livre dentro da faixa de normalidade, baseado nos valores de referência dos métodos utilizados. Participaram do estudo apenas os pacientes que apresentaram pelo menos 2 dosagens de TSH elevadas e de $\mathrm{T}_{4}$ livre normal com pelo menos 4 semanas de intervalo entre elas. Optou-se por não incluir pacientes com TSH acima de $20 \mu \mathrm{U} / \mathrm{mL}$ pelo elevado risco de progressão para hipotireoidismo manifesto, sendo iniciada reposição com $\mathrm{LT}_{4}$ e acompanhamento ambulatorial. Não foram incluídos, também, pacientes já em tratamento para hipotireoidismo com doses inadequadas de levotiroxina. Foram incluídos apenas os pacientes com idade entre 18 e 65 anos, os com HS de desenvolvimento espontâneo, ou em conseqüência de tratamento para bócio e hipertireoidismo (que tivessem evoluído com pelo menos um ano de eutireoidismo após o tratamento e antes de desenvolver HS). Foi coletado sangue para avaliação do hemograma, determinação de escórias nitrogenadas, eletrólitos, hepatograma e proteínas totais e frações com a finalidade de determinar o estado nutricional dos participantes, bem como para pesquisar a existência de doenças preexistentes ignoradas pelos participantes. Foram excluídos pacientes com doenças crônicas que pudessem interferir com a dinâmica do eixo hipotálamo-hipófise-tireóide como insuficiência renal, insuficiência cardíaca congestiva, insuficiência hepática e SIDA; os diabéticos, os com diagnóstico de doenças neuromusculares, os em uso de drogas que interferem com a função tireoideana, tais como lítio, amiodarona, iodo, citocinas, glicocorticóides em altas doses e imunossupressores, pacientes em uso de medicações que interferem no metabolismo músculo-esquelético tais como estatinas, fibratos, corticoesteróides, drogas citotóxicas. Também não foram incluídos pacientes com desnutrição. Para formar o grupo controle, foram selecionados 37 indivíduos sem disfunção tireoideana semelhantes aos casos de HS quanto à distribuição segundo sexo, idade e características sócio-econômicas e culturais. Os mesmos critérios de exclusão foram utilizados. Todos os indivíduos convidados a participar do estudo receberam explicações sobre o projeto e assinaram Termo de Consentimento Livre e Esclarecido aprovado pelo Comitê de Ética em Pesquisa do HCFF/Faculdade de Medicina/UFRJ.

\section{Avaliação clínica}

Todos os participantes foram submetidos a anamnese e exame físico na primeira visita, que foram realizados pelo mesmo examinador. Cada participante respondeu a um questionário sobre a presença de sintomas e sinais pré-definidos de hipotireoidismo baseado na es- 
cala de Billewicz modificada por Zulewski (4), e receberam uma pontuação (escore) de acordo com o encontrado (tabela 1). Para cada sintoma ou sinal presente foi dado um ponto, totalizando um máximo de 12 pontos. Receberam pontuação apenas os sintomas presentes por no máximo um ano; queixas crônicas não foram valorizadas por não poderem ser atribuídas à disfunção tireoideana, exceto aquelas que se agravaram significativamente no período. No trabalho original de Zulewski, foi adicionado 1 ponto para as mulheres com idade inferior a $\mathbf{5 5}$ anos com o objetivo de equilibrar estatisticamente os grupos, uma vez que a freqüência desses sintomas e sinais é significativamente maior nas mulheres com 55 anos ou mais. No presente trabalho, optamos por acrescentar um ponto para todos os indivíduos com idade inferior a 55 anos, inclusive os homens.

\section{Avaliação muscular}

A avaliação muscular compôs-se de anamnese dirigida, ectoscopia, avaliação da marcha, aplicação do teste muscular manual, avaliação da força de quadríceps e avaliação da força diafragmática, e foram realizadas pelo mesmo examinador.

- Anamnese dirigida: direcionada para a presença dos sintomas de fadiga, câimbra, mialgia e fraqueza muscular, levando-se em consideração a intensidade, o tempo de evolução, os grupos musculares acometidos, simetria ou assimetria dos sintomas.

- Ectoscopia: visando analisar a presença de atrofias musculares, alterações de posturas e sinais evidentes de miopatia.

- Avaliação da marcha: observando-se durante deambulação a existência de alguma alteração no padrão.

-Aplicação do teste muscular manual (TMM): foi avaliada a força de 6 grupamentos musculares (flexores da cabeça, feixe superior do trapézio, deltóide médio, supra-espinhal, glúteo máximo e glúteo médio), tendo como base a metodologia de Kendall (22), na qual o paciente é colocado em posições apro- priadas e o examinador estima o grau da força a partir da resistência manual encontrada. Foi empregada a graduação de 0 a 5 preconizadas pelo Medical Research Council (MRC) (23): grau 0 - ausência de contração; grau l - contração visível ou palpável; grau 2 - movimento ativo, mas sem vencer a ação da gravidade; grau 3 - movimento ativo vencendo a gravidade; grau 4 - movimento ativo contra grau moderado de resistência; grau 5 - força normal. Foi considerado teste anormal quando observada força inferior a $4 \mathrm{em}$ pelo menos um grupamento muscular.

- Força isométrica máxima quadríceps: medida com dinamômetro de cadeira eletromecânico IsoTeste Kroman-Thrigger em Kgf, com 3 tentativas para cada membro inferior (24). A partir do valor médio obtido, o resultado foi expresso como percentual do previsto para idade, sexo, dominância (destro ou canhoto), estatura e massa corporal, segundo os valores de referência do NIMD Consortium (25).

- Força inspiratória máxima: medida pelo registro de pressão inspiratória máxima em $\mathrm{cm} \mathrm{H}_{2} \mathrm{O}$, empregando manovacuômetro com técnica padronizada (26) e utilizando-se o valor médio de 3 tentativas para o cálculo do percentual do previsto segundo Black e Hyatt (27) em função da idade e sexo. Foi definido como normal força inspiratória superior a $80 \%$ do previsto.

\section{Avaliação laboratorial}

As dosagens séricas de $\mathrm{T}_{4}$ livre (valores de referência: $0,8-1,8 \mathrm{ng} / \mathrm{mL}$ ) e TSH (valores de referência: $0,4-4,0 \mu \mathrm{U} / \mathrm{mL}$ ) foram realizadas pelo método de quimioluminescência (kit DPC-IMMULITE). O mesmo método (quimioluminescência - kit DPCIMMULITE) foi utilizado para a determinação dos anticorpos anti-peroxidase (anti-TPO) e anti-tireoglobulina (ATTG), considerados positivos valores iguais ou superiores a $35 \mathrm{UI} / \mathrm{ml}$ e $20 \mathrm{UI} / \mathrm{ml}$, respectivamente. Foi coletado sangue de todos os participantes e as amostras foram centrifugadas em ultracentrífuga por 5 minutos a velocidade média de 10.000

Tabela 1. Sintomas e sinais de hipotireoidismo pesquisados para cálculo do escore clínico adaptado de Zulewski e col. (4).

\begin{tabular}{ll}
\hline Sintomas & \multicolumn{1}{c}{ Sinais } \\
\hline Constipação intestinal & Alentecimento do reflexo aquileu \\
Diminuição da audição & Edema periorbitário "Puffiness" \\
Diminuição da sudorese & Movimentos lentos \\
Ganho de peso & Pele fria \\
Parestesia & Pele rugosa \\
Pele seca & \\
Rouquidão & \\
\hline
\end{tabular}


rpm. O soro obtido foi estocado em freezer a $-70^{\circ} \mathrm{C}$. Posteriormente, os soros foram encaminhados para a determinação das enzimas Creatinofosfoquinase (CPK) e Desidrogenase Lactea (LDH) (Kit BheringDimension Clinical Chemistry System, método cinético UV $-37^{\circ}$ automatizado com valores de referência para mulheres, 21 a $215 \mathrm{U} / \mathrm{L}$, e para homens, 35 a $232 \mathrm{U} / \mathrm{L}$, e método piruvato lactato UV $37^{\circ}$, valores de referência: de 100 a $190 \mathrm{U} / \mathrm{L}$, respectivamente para CPK e LDH).

\section{Análise estatística}

Foram utilizados os testes estatísticos $t$ de Student e Mann-Whitney para a comparação de médias entre os dois grupos, respectivamente para as variáveis contínuas ditas de distribuição normal e não normal. $\mathrm{O}$ Teste de Mann-Whitney também foi utilizado para comparações envolvendo as variáveis ordinais entre os dois grupos. Para a comparação de proporções entre o grupo de pacientes e o grupo controle foram utilizados os testes qui-quadrado $\left(\chi^{2}\right)$ e exato de Fisher. A significância estatística foi dada ao nível de $\mathrm{p}=0,05$ (28).

\section{RESULTADOS}

Os resultados serão apresentados na seguinte seqüência: descrição das características clínicas do grupo HS e comparação de freqüências de alterações clínicas, musculares e laboratoriais entre o grupo HS e grupo controle.

\section{Características clínicas dos pacientes com HS}

Quarenta e nove pacientes (86\%) apresentaram hipotireoidismo de desenvolvimento espontâneo, 4 (7\%) haviam sido submetidos a tireoidectomia prévia para doença nodular benigna de tireóide e 4 (7\%) havi- am recebido tratamento para hipertireoidismo $(3 \mathrm{com}$ doença de Graves e 1 com nódulo autônomo). Entre os pacientes com HS de desenvolvimento espontâneo, $33(67 \%)$ tinham anticorpos anti-TPO positivo e um total de $25(51 \%)$ apresentava bócio ao exame físico.

\section{Comparação de freqüências de alterações clínicas, musculares e laboratoriais entre HS e controle e a existência de correlação entre as alteraçōes encontradas}

As idades médias de pacientes e controles foram semelhantes e ( $\mathrm{HS}=47,4$ e $\mathrm{C}=44,5$ anos, $\mathrm{p}=0,128)$. A grande maioria dos participantes de ambos os grupos foi composta de mulheres com perfis semelhantes de desenvolvimento de menopausa e uso de terapia de reposição hormonal. O IMC médio também foi semelhante nos 2 grupos. Foi observada freqüência significativamente maior de tabagistas no grupo controle $(\mathrm{p}=0,033)$. Tais resultados estão resumidos na tabela 2 .

Dezessete pacientes $(29,8 \%)$ e 22 controles $(59,5 \%)$ apresentaram escore clínico na faixa de 0 a 2 ; 34 pacientes $(59,7 \%)$ e 14 controles $(37,8 \%)$, na faixa de 3 a 5 ; e 6 pacientes $(10,5 \%)$ e 1 controle $(2,7 \%)$, na faixa superior a $5(\mathrm{p}=0,008)$ (tabela 3$)$. Quando analisado o percentual de indivíduos com escore alterado, definido como maior ou igual a 3 , observou-se anormalidade em $70,2 \%$ dos pacientes e em $38,7 \%$ dos controles $(p=0,04)$. Houve correlação entre escore alterado e as queixas de mialgia $(\mathrm{p}=0,001)$ e fraqueza $(\mathrm{p}=$ $0,010)$, e também com TMM anormal $(\mathrm{p}=0,044)$.

Os sintomas pele seca, parestesia e rouquidão foram mais freqüentes no grupo HS, enquanto ganho de peso foi a queixa mais comum nos controles. A presença de puffiness e pele espessada foi observada com maior freqüência entre os participantes do grupo HS (tabela 3).

Tabela 2. Resumo das principais características clínicas e laboratoriais dos participantes: médias e freqüências encontradas.

\begin{tabular}{lcc}
\hline Variáveis & Pacientes & Controles \\
\hline Idade média $(\mathrm{anos})^{*}$ & $47,4( \pm 9,3)$ & $44,5( \pm 9,0)$ \\
IMC médio $\left(\mathrm{kg} / \mathrm{m}^{2}\right)^{*}$ & $27,8( \pm 5,5)$ & $26,9( \pm 6,6)$ \\
Participantes do sexo feminino** & $53(93,0 \%)$ & $35(94,6 \%)$ \\
Mulheres na menopausa** & $27(51 \%)$ & $15(43 \%)$ \\
Tabagismo* & $7(12,3 \%)$ & $12(32,4 \%)$ \\
$\bullet T_{4}$ livre $(\mathrm{ng} / \mathrm{mL})^{*}$ & $1,09( \pm 0,2)$ & $1,26( \pm 0,2)$ \\
$\bullet$ TSH médio $(\mu \mathrm{U} / \mathrm{mL})^{*}$ & $7,36( \pm 2,8)$ & $1,59( \pm 0,5)$ \\
LDH médio $(\mathrm{U} / \mathrm{L})^{*}$ & $179,96( \pm 122,4)$ & $192,96( \pm 168,35)$ \\
CPK médio $(\mathrm{U} / \mathrm{L})^{*}$ & $79,85( \pm 42,51)$ & $96,70( \pm 71,20)$ \\
\hline
\end{tabular}

* Resultados expressos em média e mais desvio-padrão.

** Resultados expressos em número total de casos válidos e percentuais.

- Significância estatística ao nível de p<0,01. 
Tabela 3. Distribuição de pacientes e controles por faixa de escore e freqüência dos sintomas e sinais de hipotireoidismo encontrados em cada grupo.

\begin{tabular}{|c|c|c|}
\hline & Pacientes & Controles \\
\hline \multicolumn{3}{|l|}{ Faixas de escore } \\
\hline 0 a $2^{*}$ & $17(29,8 \%)$ & $22(59,5 \%)$ \\
\hline 3 a $5^{*}$ & $34(59,7 \%)$ & $14(37,8 \%)$ \\
\hline$>5^{\star}$ & $6(10,5 \%)$ & $1(2,7 \%)$ \\
\hline \multicolumn{3}{|l|}{ Sintomas do escore } \\
\hline Idade $<55$ anos & $44(77,2 \%)$ & $31(83,8 \%)$ \\
\hline Constipação & $11(18,3 \%)$ & $1(3,4 \%)$ \\
\hline Diminuição da audição & $9(15 \%)$ & $2(6,9 \%)$ \\
\hline Diminuição da sudorese & $6(10 \%)$ & $1(3,4 \%)$ \\
\hline Ganho de peso & $21(35 \%)$ & $15(51,7 \%)$ \\
\hline Parestesia & 27 (45\%) & $8(27,6 \%)$ \\
\hline Pele seca** & $20(33,33 \%)$ & $4(13,8 \%)$ \\
\hline Rouquidão* & $22(36,7 \%)$ & $3(10,3 \%)$ \\
\hline \multicolumn{3}{|l|}{ Sinais do escore } \\
\hline Alentecimento do reflexo aquileu & $9(15 \%)$ & $2(15 \%)$ \\
\hline Movimentos lentos & 0 & 0 \\
\hline Pele fria & $4(6,7 \%)$ & $1(3,4 \%)$ \\
\hline Pele rugosa** & $14(23,3 \%)$ & $2(6,9 \%)$ \\
\hline Puffiness* & $22(36,7 \%)$ & $3(10,3 \%)$ \\
\hline
\end{tabular}

* Significância estatística ao nível de $p<0,05$.

** Valores próximos a significância $(0,05<p<0,06)$.

Os pacientes apresentaram maior freqüência de queixas neuromusculares e alterações no teste muscular manual. Vinte e sete pacientes $(50 \%)$ e 13 controles $(35,1 \%)$ queixaram-se de câimbras $(\mathrm{p}=0,199) ; 27$ pacientes $(50 \%)$ e 7 controles $(18,9 \%)$, de mialgia $(\mathrm{p}=$ $0,004) ; 19$ pacientes $(35,2 \%)$ e 5 controles $(13,5 \%)$, de fraqueza $(\mathrm{p}=0,029)$ e 25 pacientes $(43,6 \%)$ e 13 controles $(35,1 \%)$, de fadiga $(\mathrm{p}=0,387)$. A queixa de câimbra teve correlação com mialgia $(p \leq 0,001)$ e com fraqueza $(\mathrm{p}=0,029)$. Mialgia mostrou correlação também com fraqueza $(\mathrm{p}<0,001)$ e fadiga $(\mathrm{p}<0,001)$, e fraqueza também apresentou correlação com fadiga $(\mathrm{p}=$ 0,016) (tabela 4). Mialgia apresentou correlação com menores níveis médios de força muscular de quadríceps (FMQ) $(\mathrm{p}=0,008)$. No teste muscular manual, para todos os grupamentos estudados, a redução da força foi mais freqüente no grupo de pacientes (tabela 5). O TMM esteve alterado em pelo menos um grupamento muscular em $22,2 \%$ dos pacientes e em $5,4 \%$ dos controles $(\mathrm{p}=0,029)$. Houve correlação entre TMM alterado e as queixas de mialgia $(\mathrm{p}=0,04)$ e fraqueza $(\mathrm{p}<$ $0,001)$ e também com alteração da força muscular diafragmática $(\mathrm{p}=0,018)$, mas não com força alterada de quadríceps $(\mathrm{p}=0,4 \mathrm{l})$. Não foram observadas alterações da marcha ou atrofia muscular. A força de quadríceps direito estava reduzida em 16 pacientes $(29,1 \%)$ e em 7 controles $(19,4 \%),(\mathrm{p}=0,335)$ e de quadríceps esquerdo, em 13 pacientes $(23,6 \%)$ e em 5 controles $(13,9 \%)(\mathrm{p}=$ $0,294)$. A força média de quadríceps (FMQ) esteve alte- rada em 5,5\% do grupo HS e $2,8 \%$ do controle $(\mathrm{p}=$ $0,481)$. Houve correlação entre menor intensidade da força média de quadríceps e a presença de mialgia $(\mathrm{p}=$ 0,008), mas não com os demais sintomas. A força média de quadríceps apresentou-se menor nos participantes com TMM alterado na cintura pélvica do que naqueles com esse teste normal, embora não tenha sido estatisticamente significativo $(\mathrm{p}=0,125)$. Força muscular diafragmática alterada foi observada em 36 pacientes $(64,3 \%)$ e em 15 controles $(41,7 \%)(\mathrm{p}=0,52)$, e seus valores médios foram $75 \%$ e $85 \%$ respectivamente para pacientes e controles $(\mathrm{p}=0,073)$.

Os níveis médios de $\mathrm{T}_{4}$ livre foram $1,09( \pm 0,2)$ e 1,26 $( \pm 0,2)$, respectivamente, para pacientes e controles $(\mathrm{p}<0,001)$ e os de TSH foram 7,36 $\pm 2,8$ $\mu \mathrm{U} / \mathrm{mL}$ e $1,59 \pm 0,5 \mu \mathrm{U} / \mathrm{mL}$, respectivamente $(\mathrm{p}<$ 0,001 ) (tabela 2).

A dosagem de CPK estava elevada acima dos valores de referência em 2 controles $(6,7 \%)$, mas em nenhum paciente $(\mathrm{p}=0,70)$, e a de LDH em 11 pacientes $(22,4 \%)$ e em 8 controles $(29,65 \%)(p=$ $0,583)$. Os valores médios de CPK e LDH estão expostos na tabela 4 .

\section{DISCUSSÃO}

O hipotireoidismo subclínico é uma condição prevalente e tem sido alvo de discussão na comunidade cien- 
Tabela 4. Freqüência dos sintomas neuromusculares e alterações da força muscular e das enzimas.

\begin{tabular}{|c|c|c|}
\hline & Pacientes & Controles \\
\hline $\begin{array}{l}\text { Sintomas neuromusculares } \\
\text { Câimbras } \\
\text { Mialgia* }^{*} \\
\text { Fadiga } \\
\text { Fraqueza* }\end{array}$ & $\begin{array}{l}27(50,0 \%) \\
27(50,0 \%) \\
25(43,6 \%) \\
19(35,2 \%)\end{array}$ & $\begin{array}{c}13(35,1 \%) \\
7(18,9 \%) \\
13(35,1 \%) \\
5(13,5 \%)\end{array}$ \\
\hline $\begin{array}{l}\text { Teste muscular manual } \\
\qquad \begin{array}{l}\text { Trapézio** } \\
\text { Deltóide* } \\
\text { Supra-espinhoso** } \\
\text { Flexor da cabeça* } \\
\text { Glúteo máximo** } \\
\text { Glúteo médio** }\end{array}\end{array}$ & $\begin{array}{l}8(15,1 \%) \\
11(20,8 \%) \\
8(15,1 \%) \\
6(11,3 \%) \\
5(9,4 \%) \\
5(9,4 \%)\end{array}$ & $\begin{array}{l}1(2,7 \%) \\
0 \\
1(2,7 \%) \\
0 \\
0 \\
0\end{array}$ \\
\hline $\begin{array}{l}\text { Dinamômetro } \\
\qquad \begin{array}{l}\text { Quadríceps direito } \\
\text { Quadríceps esquerdo }\end{array}\end{array}$ & $\begin{array}{l}16(29,1 \%) \\
16(29,1 \%)\end{array}$ & $\begin{array}{c}7(19,4 \%) \\
5(13,9)\end{array}$ \\
\hline Força muscular inspiratória & $36(64,3 \%)$ & $15(41,7 \%)$ \\
\hline $\begin{array}{r}\text { Enzimas musculares } \\
\mathrm{CPK} \\
\mathrm{LDH}\end{array}$ & $\begin{array}{c}0 \\
11(22,4 \%)\end{array}$ & $\begin{array}{l}2(6,70 \%) \\
8(29,6 \%)\end{array}$ \\
\hline
\end{tabular}

* Significância estatística ao nível de $p<0,05$.

** Valores próximos da significância $(p=0,054$ e 0,055).

tífica há pelo menos 20 anos (29). No entanto, ainda não há consenso quanto às indicações de tratamento com $\mathrm{LT}_{4}$ e aos seus reais benefícios $(30,31)$. O maior temor dos pesquisadores tem sido utilizar desnecessariamente a $\mathrm{LT}_{4}$. Esse fato é especialmente importante nas populações mais idosas, nas quais a prevalência de HS é maior, por haver maior suscetibilidade aos efeitos colaterais do tratamento (32).

No grupo estudado, foi encontrada uma freqüência significativamente maior de participantes do sexo feminino, com uma relação de $13 / 1$ em relação ao sexo masculino. A idade média dos participantes foi de 47,4 $( \pm 9,3)$ anos e $51 \%$ das mulheres do estudo já estavam na menopausa. Esses dados estão em total acordo com importantes estudos de prevalência, como o de Whickham (12) e o do Colorado (13), e parecem refletir o comportamento epidemiológico do HS em nossa sociedade. A etiologia mais freqüente encontrada foi a tireoidite auto-imune, também em concordância com os dados da literatura (17). Desenvolvimento espontâneo de HS ocorreu em $86 \%$ dos pacientes, e $67 \%$ desses tiveram dosagem positiva de anticorpos anti-TPO.

$\mathrm{O}$ grupo HS apresentou níveis séricos de $\mathrm{T}_{4}$ livre médios menores do que os controles com significância estatística. Os mesmos achados foram encontrados no estudo de Whickham (12). Staub e col. (33) encontraram diferença estatisticamente significativa dos níveis de $\mathrm{T}_{4}$ livre até mesmo em pacientes com níveis de TSH discretamente acima do normal. Muitas vezes, pacientes com alterações marcantes nos hormônios tireoideanos circulantes exibem poucos sintomas, enquanto outros com alterações discretas são muito sintomáticos; contudo os níveis significativamente mais baixos de $\mathrm{T}_{4}$ livre nos pacientes com HS sugerem seu provável papel na patogenia dessa condição. A grande maioria dos pacientes apresentou níveis de TSH discretamente aumentados, entre 4 e 8 $\mu \mathrm{U} / \mathrm{mL}$, o que também está de acordo com os estudos mais importantes nos quais cerca de $55 \%$ a $85 \%$ dos indivíduos apresentavam níveis de TSH entre 5 e $10 \mu \mathrm{U} / \mathrm{mL}$ (2). Na literatura, níveis de TSH acima de $12 \mu \mathrm{U} / \mathrm{mL}$ parecem correlacionar-se com uma maior freqüência de alterações clínicas e metabólicas, mas o mesmo não foi verificado no presente trabalho (35).

Os pacientes HS apresentaram faixas mais elevadas de escore clínico, mostrando um padrão semelhante ao descrito por Zulewski (4). Uma freqüência significativamente maior de sintomas e sinais de hipotireoidismo poderia estar representando um inadequado efeito dos HT nos tecidos-alvo. O escore clínico é facilmente aplicável e parece ser uma forma 
simples e rápida de estimar o grau de comprometimento do HS, podendo auxiliar na conduta terapêutica. Dentre os achados do escore, os sintomas de rouquidão e pele seca foram significativamente mais prevalentes. Eles foram considerados por Zulewski importantes preditores de hipofunção tireoideana. Cooper e col. (3) também encontraram pele seca como uma queixa comum. No presente estudo, rouquidão foi um achado significativamente mais prevalente no grupo HS. Na literatura, contudo, tem sido associada a quadros de franco hipotireoidismo, em geral de longa evolução (36). A explicação para a freqüência maior desse sintoma no grupo HS não está clara, mas pode sugerir que já no HS se iniciem as alterações fisiopatológicas que levam a esse achado. O tempo de evolução de HS poderia influenciar no desenvolvimento dessa condição, mas não foi possível determinar esse tempo na grande maioria dos pacientes (37). Na prática clínica, a queixa de rouquidão persistente, especialmente se tiver associação temporal com o desenvolvimento de HS, pode sugerir um grau mais avançado de HS e até mesmo maior risco para desenvolvimento de HM. A constipação intestinal foi um achado pouco comum e apresentou freqüência semelhante ao do grupo controle, o que também foi observado por Cooper (3). Possivelmente é um sintoma inespecífico e de pouco valor na prática, dada a grande prevalência na população feminina em geral. A presença de puffiness infra-orbitário foi maior no HS e já havia sido apontada por Zulewski (4) como um dos sinais com maior valor preditivo positivo para estimativa de hipotireoidismo em um paciente com suspeita clínica. Além disso, é um sinal facilmente identificável, o que o viabiliza como um bom indicador de disfunção tireoideana na prática. O achado de freqüências semelhantes de alentecimento do reflexo aquileu entre HS e controle está em desacordo com Zulewski (4), que o considerava um sinal de elevado valor preditivo para o diagnóstico de hipotireoidismo. A análise puramente visual sem o auxílio de um refletômetro pode ter sido a causa para tal discordância. Monzani e cols., que utilizaram aparelhagem adequada, encontraram maior freqüência de alterações do reflexo aquileu no HS (38). Esses autores encontraram freqüências significativamente maiores de sintomas neuromusculares (parestesias, câimbras, fadiga e fraqueza muscular) no HS, semelhante ao encontrado no presente estudo. As queixas mais freqüentes foram mialgia $(31,1 \%)$ e fraqueza muscular $(22,3 \%)$, e, embora não tenha apresentado significância estatística, câimbra também foi mais freqüente no HS (14,9\%). Outros autores também têm observado maior freqüência dessas queixas.
Rodolico e cols. (39) descreveram 3 pacientes com queixas de câimbras, mialgia e episódios de fraqueza generalizada. Wilson e Walton (40) descreveram o surgimento de queixas como câimbra e mialgia em pacientes que receberam dose terapêutica com ${ }^{131}$ I para tratamento de hipertireoidismo, que precederam o diagnóstico laboratorial de hipotireoidismo. Cooper (3) também observou que fadiga e câimbras foram mais comuns em pacientes com HS, e que melhoraram significativamente após início de tratamento com $\mathrm{LT}_{4}$. Fessel e cols. (4l) estudaram três pacientes nos quais os sintomas musculares precederam o diagnóstico laboratorial de hipotireoidismo. A deficiência dos hormônios tireoideanos prejudica o metabolismo energético do miócito, levando à diminuição da velocidade de contração muscular e de seu relaxamento $(42,43)$, e também afeta a integridade das membranas celulares que leva a necrose muscular e liberação de enzimas na circulação sangüínea $(44,45)$. A grande prevalência de sintomas músculo-esqueléticos na literatura e sua correlação com alterações no TMM no presente trabalho, sugerem que a disfunção mínima da tireóide já interfira com a função muscular. Contudo, não foi observada diferença entre a força muscular de quadríceps entre pacientes e controles e, ao contrário do que se esperava, não houve correlação entre a FMQ e o TMM. Esse fato pode sugerir que o dinamômetro de cadeira não seja um teste suficientemente sensível para captar as alterações provocadas pela disfunção mínima da tireóide no músculo esquelético.

Os níveis de CPK de pacientes e controles do presente estudo estavam dentro da faixa de normalidade. Esses dados são diferentes dos encontrados por Rodolico e cols. (46), que descreveram elevação dessa enzima em 90\% dos pacientes, mesmo na ausência de outros sinais de hipotireoidismo, mas estão de acordo com os descritos por Monzani e cols. (38), que também não encontraram elevação de CPK em nenhum paciente com HS. Possivelmente a elevação dos níveis de CPK esteja relacionada à progressão da miopatia, $\mathrm{e}$ por isso muitas vezes pode não estar elevada no HS.

HS é uma doença prevalente e aparentemente relacionada à piora da qualidade de vida, em função do que foi encontrado nesse trabalho e no que tem sido descrito na literatura. A correlação entre a presença de sintomas neuromusculares e alteração do TMM com o escore clínico sugere que o HS não seja apenas uma alteração laboratorial, mas uma doença na qual pode haver o comprometimento global dos órgãos-alvo. Tendo como base o princípio de que o objetivo de um tratamento é melhorar a qualidade de vida e reduzir a morbi-mortalidade de uma doença nos indivíduos 
acometidos, o tratamento deve ser individualizado. Para tanto, é necessário levar em consideração os níveis de TSH e/ou positividade de anticorpos antitireoideanos, como é defendido por diversos autores, mas também a existência de sinais e sintomas que sugiram hipofunção tireoideana, especialmente os neuromusculares. A terapia com $\mathrm{LT}_{4}$ evitaria a progressão do quadro clínico, prevenindo a evolução para uma verdadeira miopatia, assim proporcionando melhora da qualidade de vida desses pacientes.

\section{AGRADECIMENTOS}

Ao Laboratório Sanofi-Synthelabo, pelo apoio concedido.

\section{REFERÊNCIAS}

1. Ayala AR, Wartofsky L. Minimally symptomatic (subclinical) hypothyroidism. The Endocrinologist 1997;7:44-50

2. Cooper DS. Subclinical hypothyroidism. N Engl J Med 2001;345(4):260-5

3. Cooper DS, Halpern R, Wood LC, Levin AA, Ridgway C. L-Thyroxine therapy in subclinical hypothyroidism: a double-blind, placebo-controlled trial. Ann Intern Med 1984:101:18-24.

4. Zulewski $H$, Müller B, Exer P, Miserez AR, Staub JJ. Estimation of tissue hypothyroidism by a new clinical score: evaluation of patients with various grades of hypothyroidism and controls. J Clin Endocrinol Metab 1997:8:771-6.

5. Misiunas A, Niepomniszcze H, Ravera B, Faraj G, Faure E. Peripheral neuropathy in subclinical hypothyroidism. Thyroid 1995;5:283-6.

6. Cakir M, Samanci N, Balci N, Balci MK. Musculoskeletal manifestation in patients with thyroid disease. Clin Endocrinol 2003:59:162-7.

7. Teixeira PFS, Reis FAA, Reuters VS, Almeida CP, Vaisman M. Hipotireoidismo subclínico e risco cardiovascular. Rev SOCERJ 2004; 17:50-7.

8. Biondi B, Palmieri EA, Lombardi G, Fazio S. Effects of subClinical thyroid dysfunction on the heart. Ann Intern Med 2002; 137(11):904-14.

9. Klein I, Ojamaa K. Thyroid hormone and the cardiovascular system. N Engl J Med 2001;344:501-9.

10. Placidi GP, Boldrini M, Patronelli A, Fiore E, Chiovato L, Perugi $G$, et al. Prevalence of psychiatric disorders in thyroid diseased patients. Neuropsychobiology 1998:38:222-5

11. Volpato S, Guaralnik JM, Fried LP, Remaley AT, Cappola AR, Launer LJ, et al. Serum thyroxine level and cognitive decline in euthyroid older women. Neurology 2002;58:1055-61.
12. Tunbridge WM, Evered DC, Hall R, Appleton D, Brewis $M$, Clark $\mathrm{F}$, et al. The spectrum of thyroid disease in a community: the Whickham survey. Clin Endocrinol (Oxf) 1977;7:481-93.

13. Canaris GJ, Manowitz NR, Mayor G, Ridgway C. The Colorado thyroid disease prevalence study. Arch Intern Med 2000; 160:526-34.

14. Samuels MH. Subclinical thyroid disease in the elderly. Thyroid 1998;8:803-11.

15. Huber G, Staub JJ, Meier C, Mitrache C, Guglielmetti M, Huber $\mathrm{P}$, et al. Prospective study of the spontaneous course of subclinical hypothyroidism: prognostic value of thyrotropin, thyroid reserve, and thyroid antibodies. J Clin Endocrinol Metab 2002;87:3221-6.

16. Vanderpump MPJ, Tunbridge WMG, French JM, Appleton $D$, Bates $D$, Clark $F$, et al. The incidence of thyroid disorders in the community: a twenty-year follow-up of the Wickham survey. Clin Endocrinol (Oxf) 1995;43:55-68.

17. Hollowell JG, Staehling NW, Flanders WD, Hannon WH, Gunter EW, Spencer CA, et al. Serum TSH, T4 and thyroid antibodies in the united states population (1988 to 1994): national health and nutrition examination survey (NHANES III). J Clin Endocrinol Metab 2002;87:489-99.

18. Owen PJ, Lazarus JH. Subclinical hypothyroidism: the case for treatment. Trends Endocrinol Metab 2003; 14 : 257-61.

19. Vanderpump M. Subclinical hypothyroidism: the case against treatment. Trends Endocrinol Metab 2003;14: 262-6.

20. Nyström E, Caidahl K, Fager G, Wikkelso C, Lundberg PA, Lindstedt $G$. A double-blind cross-over 12-month study of L-thyroxine treatment of women with subclinical hypothyroidism. Clin Endocrinol 1988;29:63-75.

21. Chu JW, Crapo LM. Should mild hypothyroidism be treated? Am J Med 2002; 1 12:422-3.

22. Daniels L, Worthingham C. Provas de Função Muscular. Rio de Janeiro: Interamericana; 1973.

23. Medical Research Council. Aids to the Investigation of Peripheral nerve Injuries. Nerve Injuries Committee, War memorandum, nr. 7. London: H.M. Stationery Office; 1942.

24. The National Isometric Muscle Strength (NIMS) Database Consortium. Muscular Weakness Assessment: Use of Normal isometric Strength Data. Arch Phys Med Rehabil 1996;77:1251-5.

25. Rufino R. Testes de função respiratória. Rio de Janeiro: Atheneu; 2000.

26. Picado C, Fiz JA, Montserrat JM, Grau JM, FernandezSola J, Luengo MT, et al. Respiratory and skeletal muscle function in steroid-dependent bronchial asthma. Am Rev Respir Dis 1990;141:14-20.

27. Black LF, Hyatt RE. Maximal respiratory pressures: normal values and relationship to age and sex. Am Rev Respir Dis 1969:99(5):696-702

28. Rodrigues LC, Werneck GL. Estudos caso-controle. In: Medronho RA. Epidemiologia. $10^{a}$ ed. Rio de Janeiro: Atheneu; 2002. pp.175-89. 
29. Cooper DS. Subclinical thyroid disease: a clinician's perspective. Ann Intern Med 1998;129:135-8.

30. Mc Dermott MT, Ridgway EC. Subclinical hypothyroidism is mild thyroid failure and should be treated. J Clin Endocrinol Metab 2001;86:4585-9.

31. Chu JW, Crapo LM. The treatment of subclinical hypothyroidism is seldom necessary. J Clin Endocrinol Metab 2001;86:4591-9.

32. Sawin CT, Chopra D, Azizi F, Mannix JE, Bacharach P. The aging thyroid. Increased prevalence of elevated serum thyrotropin levels in the elderly. JAMA 1979;242:247-50.

33. Staub JJ, Althaus BU, Engler H, Ryff AS, Trabucco P, Marquardt $\mathrm{K}$, et al. Spectrum of subclinical and overt hypothyroidism: effect on thyrotropin, prolactin, and thyroid reserve, and metabolic impact on peripheral target tissues. Am J Med 1992;92:631-41.

34. Cooper DS, Halpern R, Wood LC, Levin AA, Ridgway C. L-Thyroxine therapy in subclinical hypothyroidism: a double-blind, placebo-controlled trial. Ann Intern Med 1984:101:18-24.

35. Surkis Ml, Ortiz E, Daniels GH, Sawin CT, Col NF, Cobin RH, et al. Subclinical thyroid disease. JAMA 2004;291:228-38.

36. Meier C, Trittibach P, Guglielmetti M, Staub JJ, Muller B. Serum thyroid stimulating hormone in assessment of severity of tissue hypothyroidism in patients with overt primary thyroid failure: cross sectional survey. BMJ 2003:326:311-2.

37. Vanderpump MPJ, Tunbridge WMG. Epidemiology and prevention of clinical and subclinical hypothyroidism. Thyroid 2002; 12:839-47.

38. Monzani F, Caraccio N, Del Guerra P, Casolaro A, Ferrannini E. Neuromuscular symptoms and dysfunction in subclinical hypothyroid patients: beneficial effect of $\mathrm{LT}_{4}$ replacement therapy. Clin Endocrinol (Oxf) 1999:51: $237-42$.
39. Rodolico C, Toscano A, Benvenga S. Skeletal muscle disturbances may precede clinical and laboratory evidence of autoimune hypothyroidism. J Neurol 1998; 245:555-6.

40. Wilson J, Walton JN. Some muscular manifestations of hypothyroidism. J Neurol Neurosurg Psychiatry 1959:22:320-4

41. Fessel WJ. Myopathy of hypothyroidism. Ann Rheum Dis 1968;25:590-6

42. Zürcher RM, Horber FF, Grünig BE, Frey FJ. Effect of thyroid dysfunction on thigh muscle efficiency. J Clin Endocrinol Metab 1989:69:1082-6.

43. Duyff RF, Van den Bosch J, Laman DM, van Loon BJ, Linssen WH. Neuromuscular findings in thyroid dysfunction: a prospective clinical and electrodiagnostic study. J Neurol Neurosurg Psychiatry 2000;68:750-5.

44. Beyer IW, Karmali R, Demeester-Mirkine N, Cogan E, Fuss MJ. Serum creatine kinase levels in overt and subclinical hypothyroidism. Thyroid 1998;8:1029-31.

45. Monzani F, Caraccio N, Siciliano G, Manca L, Murri L, Ferrannini E. Clinical and biochemical features of muscle dysfunction in subclinical hypothyroidism. J Clin Endocrinol Metab 1997;82:3315-8.

46. Rodolico C, Toscano A, Benvenga S, Mazzeo A, Bartolone S, Bartolone L, et al. Myopathy as the persistently isolated symptomatology of primary autoimune hypothyroidism. Thyroid 1998;8:1033-8.

\section{Endereço para correspondência:}

Vaneska Spinelli Reuters

Rua Alfredo Ceschiatti 155, Bloco 2, apto. 901

22275-045 Rio de Janeiro, RJ

E-mail: vaneskareuters@aol.com 